\title{
Sampling experience in a cherry plantation
}

\author{
Polyák, N. I., Csizmazia, Z., Vaszil, B., Ancza, E., Nyéki, J. \& Szabó, Z. \\ University of Debrecen Centre for Agricultural and Applied Economic Sciences, \\ H-4032 Debrecen, Böszörményi út 138., Hungary
}

\begin{abstract}
Summary: Experiments in a cherry plantation were performed to find out that samples taken from various parts of the foliage of the tree what extent represent the whole tree. One tree from three different cherry varieties was selected. In the selection, we tried to form a good representation of the foliage of the orchard. 8 sampling locations were designated on each tree, in two different heights and four different directions according to the points of the compass. We measured the main sizes of the fruits in three orthogonal dimensions with a digital slide gauge with an accuracy of $0.01 \mathrm{~mm}$; the mass of each cherry by an analytical balance, with an accuracy of $0.001 \mathrm{~g}$; the mass of the stones with the same analytical balance, and then calculated the stone-pulp ratio. The measured and calculated data are used to characterize the sample in question.
\end{abstract}

Keywords: sampling, sampling location, orientation, physical properties

\section{Introduction}

Experiments in a cherry plantation were performed to find out that samples taken from various parts of the foliage of the tree what extent represent the whole tree. One tree from the Linda, Germersdorfi and Stella varieties were selected for the tests. The selection of trees tried to form a good representation of the foliage of the orchard. 8 sampling locations were designated in two different heights and four different directions according to the points of the compass.

The samples were marked as follows:

1. Lower North $(\mathrm{L} / \mathrm{N})$;

2. Upper North $(\mathrm{U} / \mathrm{N})$;

3. Lower West $(\mathrm{L} / \mathrm{W})$;

4. Upper West (U/W);

5. Lower South $(\mathrm{L} / \mathrm{S})$;

6. Upper South (U/S);

7. Lower East $(\mathrm{L} / \mathrm{E})$;

8. Upper East (U/E).
The samples, which were identified by the date, were taken in 3 stages of the maturation.

15-15 fruits were selected from each sample, taking the rules of sampling from a set into consideration. Consequently, the characteristics of $3 \times 3 \times 8 \times 15=1080$ pieces of fruit were measured.

The following data were recorded:

1. the main sizes of the fruit in three orthogonal dimensions with a digital slide gauge with an accuracy of $0.01 \mathrm{~mm}$;

2. the mass of each sweet cherry by an analytical balance, with an accuracy of $0.001 \mathrm{~g}$;

3 . the mass of the stones with the same analytical balance;

4. The samples, for subsequent image processing, were photographed together (Fig. 1) and separately (Fig. 2). Photos taken from the Germersdorfi variety are given here.

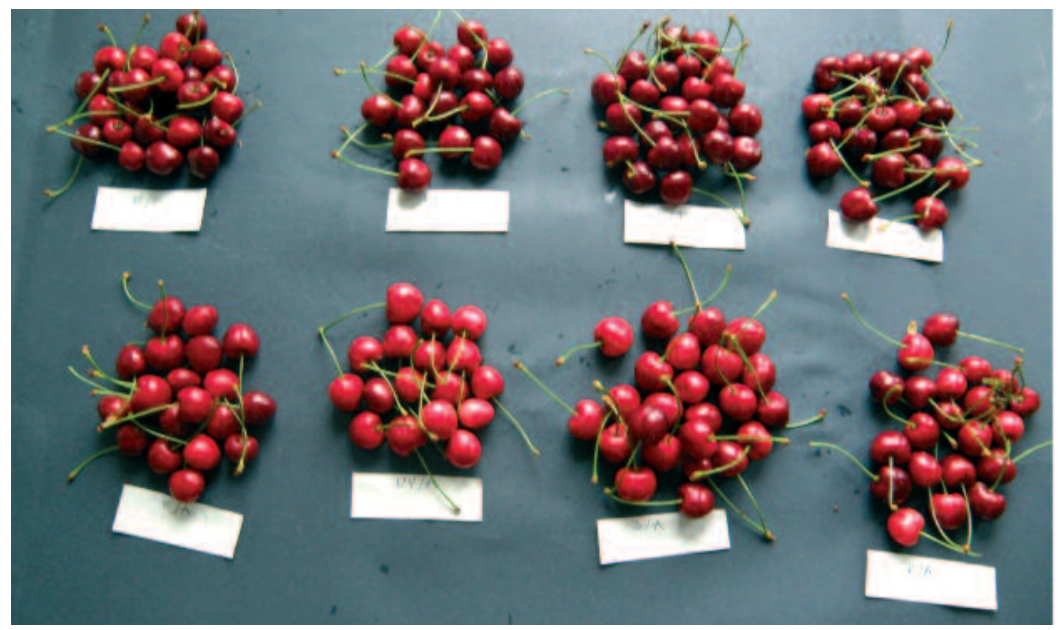

Fig. 1: Samples of Germersdorfi from 8 different sampling locations

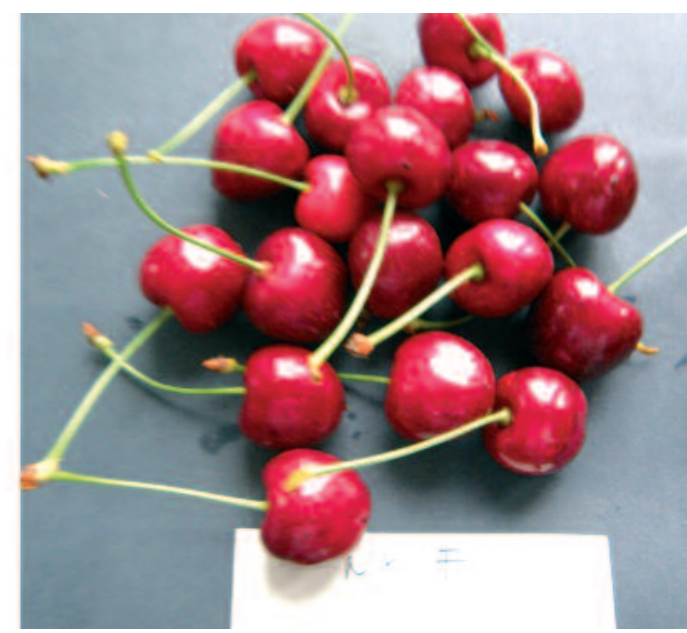

Fig. 2: The sample marked as (U/W) 
From the measured data we determined the following characteristics of the fruits for each sampling points:

- the smallest and largest values of the size;

- the average value of the size;

- the standard deviation of the size;

- the average mass of the fruit;

- the average mass of the stone;

- the average stone-pulp ratio.

The deviations found between the sampling locations were compared.

\section{Results}

The fruit sizes has been identified that the height was determined as the size parallel with the stem, i.e. the long axis (y coordinate); perpendicularly to that, the width was measured at the largest diameter (x coordinate); and perpendicularly to that, the thickness ( $\mathrm{z}$ coordinate).

The maximum and the minimum size, the average value and standard deviation of these three sizes were determined for each sample.

\section{Width}

The values of the widths of the samples, taken from two different heights and four different directions, for three varieties of cherry are given in Table 1 . Whereas other studies

Table 1: The values of the widths of the samples

\begin{tabular}{|c|c|c|c|c|c|c|c|}
\hline \multicolumn{8}{|c|}{ Linda } \\
\hline & & & North & West & South & East & Diff. \\
\hline \multirow{9}{*}{14 June } & \multirow{4}{*}{ Lower } & Min. & 20,80 & 21,16 & 21,16 & 23,61 & \\
\hline & & Max. & 24,67 & 25,63 & 25,21 & 25,43 & \\
\hline & & Mean & 23,58 & 23,30 & 23,99 & 24,57 & $5 \%$ \\
\hline & & Std. dev. & 1,21 & 1,27 & 0,81 & 0,55 & \\
\hline & \multirow{5}{*}{ Upper } & Min. & 22,50 & 21,36 & 22,73 & 21,53 & \\
\hline & & Max. & 25,67 & 26,23 & 24,53 & 25,31 & \\
\hline & & Mean & 24,28 & 24,30 & 23,78 & 23,68 & $3 \%$ \\
\hline & & Std. dev. & 0,94 & 1,30 & 0,47 & 1,04 & \\
\hline & & Diff.(L;U) & $3 \%$ & $4 \%$ & $1 \%$ & $4 \%$ & \\
\hline \multirow{9}{*}{17 June } & \multirow{4}{*}{ Lower } & Min. & 22,83 & 24,54 & 23,69 & 24,26 & \\
\hline & & Max. & 27,96 & 27,05 & 28,14 & 28,76 & \\
\hline & & Mean & 25,24 & 25,52 & 25,28 & 26,36 & $4 \%$ \\
\hline & & Std. dev. & 1,50 & 0,70 & 1,17 & 1,28 & \\
\hline & \multirow{5}{*}{ Upper } & Min. & 22,83 & 25,02 & 22,42 & 23,15 & \\
\hline & & Max. & 27,21 & 28,44 & 26,06 & 26,97 & \\
\hline & & Mean & 25,05 & 26,12 & 24,86 & 25,10 & $5 \%$ \\
\hline & & Std. dev. & 1,13 & 1,00 & 0,79 & 0,84 & \\
\hline & & Diff.(L;U) & $1 \%$ & $2 \%$ & $2 \%$ & $5 \%$ & \\
\hline \multirow{9}{*}{21 June } & \multirow{4}{*}{ Lower } & Min. & 25,52 & 23,42 & 22,60 & 24,29 & \\
\hline & & Max. & 29,28 & 29,81 & 28,03 & 28,89 & \\
\hline & & Mean & 27,91 & 26,68 & 25,46 & 27,12 & $10 \%$ \\
\hline & & Std. dev. & 0,98 & 1,63 & 1,56 & 1,20 & \\
\hline & \multirow{5}{*}{ Upper } & Min. & 24,30 & 24,20 & 20,68 & 23,61 & \\
\hline & & Max. & 27,86 & 28,20 & 25,68 & 28,32 & \\
\hline & & \begin{tabular}{|l|} 
Mean \\
\end{tabular} & 26,44 & 26,50 & 23,45 & 25,57 & $13 \%$ \\
\hline & & Std. dev. & 1,16 & 1,21 & 1,32 & 1,18 & \\
\hline & & Diff.(L;U) & $6 \%$ & $1 \%$ & $9 \%$ & $6 \%$ & \\
\hline
\end{tabular}

\begin{tabular}{|c|c|c|c|c|c|c|c|}
\hline \multicolumn{8}{|c|}{ Germersdorfi } \\
\hline & & & North & West & South & East & Diff. \\
\hline \multirow{9}{*}{14 June } & \multirow{4}{*}{ Lower } & Min. & 22,21 & 21,78 & 21,75 & 20,37 & \\
\hline & & Max. & 25,48 & 26,39 & 25,96 & 25,70 & \\
\hline & & Mean & 23,51 & 23,84 & 23,95 & 23,46 & $2 \%$ \\
\hline & & Std. dev. & 0,86 & 1,24 & 1,30 & 1,51 & \\
\hline & \multirow{5}{*}{ Upper } & Min. & 21,54 & 22,17 & 21,19 & 22,45 & \\
\hline & & Max. & 24,68 & 26,41 & 25,64 & 26,85 & \\
\hline & & Mean & 23,14 & 24,74 & 23,98 & 24,40 & $7 \%$ \\
\hline & & Std. dev. & 1,03 & 1,03 & 1,41 & 1,33 & \\
\hline & & Diff.(L;U) & $2 \%$ & $4 \%$ & $0 \%$ & $4 \%$ & \\
\hline \multirow{9}{*}{17 June } & \multirow{4}{*}{ Lower } & Min. & 23,59 & 23,09 & 23,94 & 22,14 & \\
\hline & & Max. & 27,02 & 26,02 & 27,60 & 25,99 & \\
\hline & & Mean & 25,58 & 24,69 & 25,23 & 24,55 & $4 \%$ \\
\hline & & Std. dev. & 0,92 & 0,88 & 1,07 & 0,99 & \\
\hline & \multirow{5}{*}{ Upper } & Min. & 22,73 & 23,44 & 23,14 & 23,33 & \\
\hline & & Max. & 26,37 & 28,45 & 26,60 & 26,09 & \\
\hline & & Mean & 25,15 & 25,19 & 25,08 & 24,44 & $3 \%$ \\
\hline & & Std. dev. & 1,03 & 1,26 & 0,89 & 0,80 & \\
\hline & & Diff.(L;U) & $2 \%$ & $2 \%$ & $1 \%$ & $0 \%$ & \\
\hline \multirow{9}{*}{21 June } & \multirow{4}{*}{ Lower } & Min. & 24,64 & 22,21 & 24,97 & 21,76 & \\
\hline & & Max. & 29,42 & 28,00 & 28,88 & 27,38 & \\
\hline & & Mean & 26,08 & 24,72 & 27,00 & 24,95 & $9 \%$ \\
\hline & & Std. dev. & 1,30 & 1,61 & 1,13 & 1,65 & \\
\hline & \multirow{5}{*}{ Upper } & Min. & 22,64 & 22,60 & 23,77 & 22,64 & \\
\hline & & Max. & 27,34 & 28,35 & 27,80 & 28,11 & \\
\hline & & Mean & 25,73 & 25,83 & 26,02 & 25,26 & $3 \%$ \\
\hline & & Std. dev. & 1,43 & 1,40 & 0,98 & 1,30 & \\
\hline & & Diff.(L;U) & $1 \%$ & $5 \%$ & $4 \%$ & $1 \%$ & \\
\hline & & & Ste & & & & \\
\hline & & & North & West & South & East & Diff. \\
\hline \multirow{9}{*}{14 June } & \multirow{4}{*}{ Lower } & Min. & 20,04 & 19,22 & 19,15 & 19,66 & \\
\hline & & Max. & 22,79 & 22,11 & 23,35 & 23,43 & \\
\hline & & Mean & 21,45 & 21,01 & 21,79 & 21,32 & $4 \%$ \\
\hline & & Std. dev. & 0,85 & 0,70 & 1,03 & 1,19 & \\
\hline & \multirow{5}{*}{ Upper } & Min. & 19,64 & 19,92 & 19,36 & 17,04 & \\
\hline & & Max. & 23,24 & 23,06 & 22,68 & 21,45 & \\
\hline & & Mean & 21,98 & 21,26 & 21,04 & 19,91 & $10 \%$ \\
\hline & & Std. dev. & 0,99 & 0,95 & 0,99 & 1,20 & \\
\hline & & Diff.(L;U) & $2 \%$ & $1 \%$ & $4 \%$ & $7 \%$ & \\
\hline \multirow{9}{*}{17 June } & \multirow{4}{*}{ Lower } & Min. & 20,81 & 21,16 & 21,31 & 20,61 & \\
\hline & & Max. & 24,92 & 24,16 & 23,22 & 23,81 & \\
\hline & & Mean & 22,32 & 22,54 & 22,35 & 22,66 & $2 \%$ \\
\hline & & Std. dev. & 1,24 & 0,97 & 0,65 & 0,94 & \\
\hline & \multirow{5}{*}{ Upper } & Min. & 19,13 & 19,96 & 19,92 & 20,39 & \\
\hline & & Max. & 22,07 & 23,58 & 22,33 & 23,44 & \\
\hline & & Mean & 20,38 & 21,72 & 21,02 & 21,27 & $7 \%$ \\
\hline & & Std. dev. & 0,78 & 0,98 & 0,70 & 0,83 & \\
\hline & & Diff.(L;U) & $10 \%$ & $4 \%$ & $6 \%$ & $7 \%$ & \\
\hline & & Min. & 22,38 & 19,66 & 21,29 & 21,75 & \\
\hline & J ower & Max. & 27,37 & 23,67 & 23,98 & 24,37 & \\
\hline & Lower & Mean & 24,73 & 21,58 & 22,86 & 23,17 & $15 \%$ \\
\hline & & Std. dev. & 1,75 & 1,01 & 0,82 & 0,83 & \\
\hline 21 June & & Min. & 20,56 & 20,37 & 19,41 & 20,35 & \\
\hline & & Max. & 24,26 & 23,49 & 23,62 & 24,00 & \\
\hline & Upper & Mean & 22,19 & 22,10 & 22,05 & 22,23 & $1 \%$ \\
\hline & & Std. dev. & 1,07 & 0,86 & 1,06 & 1,15 & \\
\hline & & Diff.(L;U) & $11 \%$ & $2 \%$ & $4 \%$ & $4 \%$ & \\
\hline
\end{tabular}


attribute a significant role to the diameter of the cherries (here width), so the size of the widths of the three size-related results are presented. According to the data, shown in the table, it can be generally concluded, that there is a substantial difference in sizes of samples taken from different heights and different directions.

Analysing the certain varieties, the differences of the average widths of Linda varied between $3-13 \%$ in the function of orientation. The maximum deviation was measured at the last sampling time, i.e. when the cherries were ripe. The differences of the average widths varied between 1-9\% when the lower and upper sampling locations were compared.

The changes can be seen clearly in Fig. 3, considering the sampling time, the orientation and the height of the foliage. This figure consists of three parts, and shows the values of widths for Linda in three sampling dates. During the assessment of the diagrams it must be taken into account that

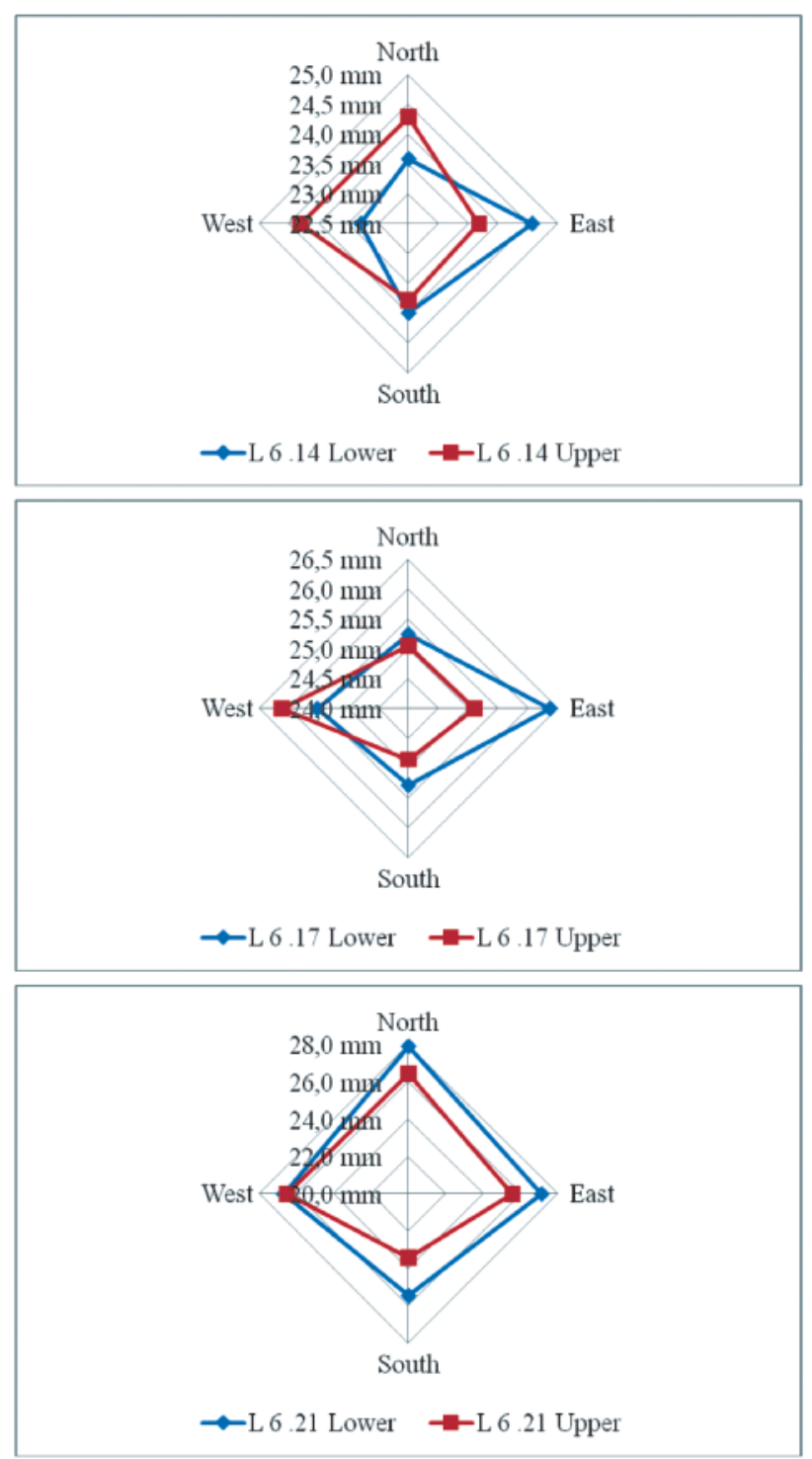

Fig. 3: The width in the function of time, orientation and height in the case of Linda [mm] the sizes, generated in each part of the figure, are different, so the reference to the same values is essential. It can be easily followed with the help of the dimensioning and the given values. It is important to stress this, because disregarding this, from the illustrations it might seem as if the size of the fruit would have been greater at the earlier dates of sampling.

However, taking into account the actual dimensions of the width, the change of the size of the width illustrates the parallel increase of the fruit with the maturation, and also that this increase may be different for each orientation.

In the case of Germersdorfi the differences of the average widths varied between $3-13 \%$ in the function of orientation. The maximum deviation was measured at the last sampling time, i.e. when the cherries were ripe. The differences of the average widths varied between $0-5 \%$ when the lower and upper sampling locations were compared.

The changes can be seen clearly in Fig. 4, considering the sampling time, the orientation and the height of the foliage.

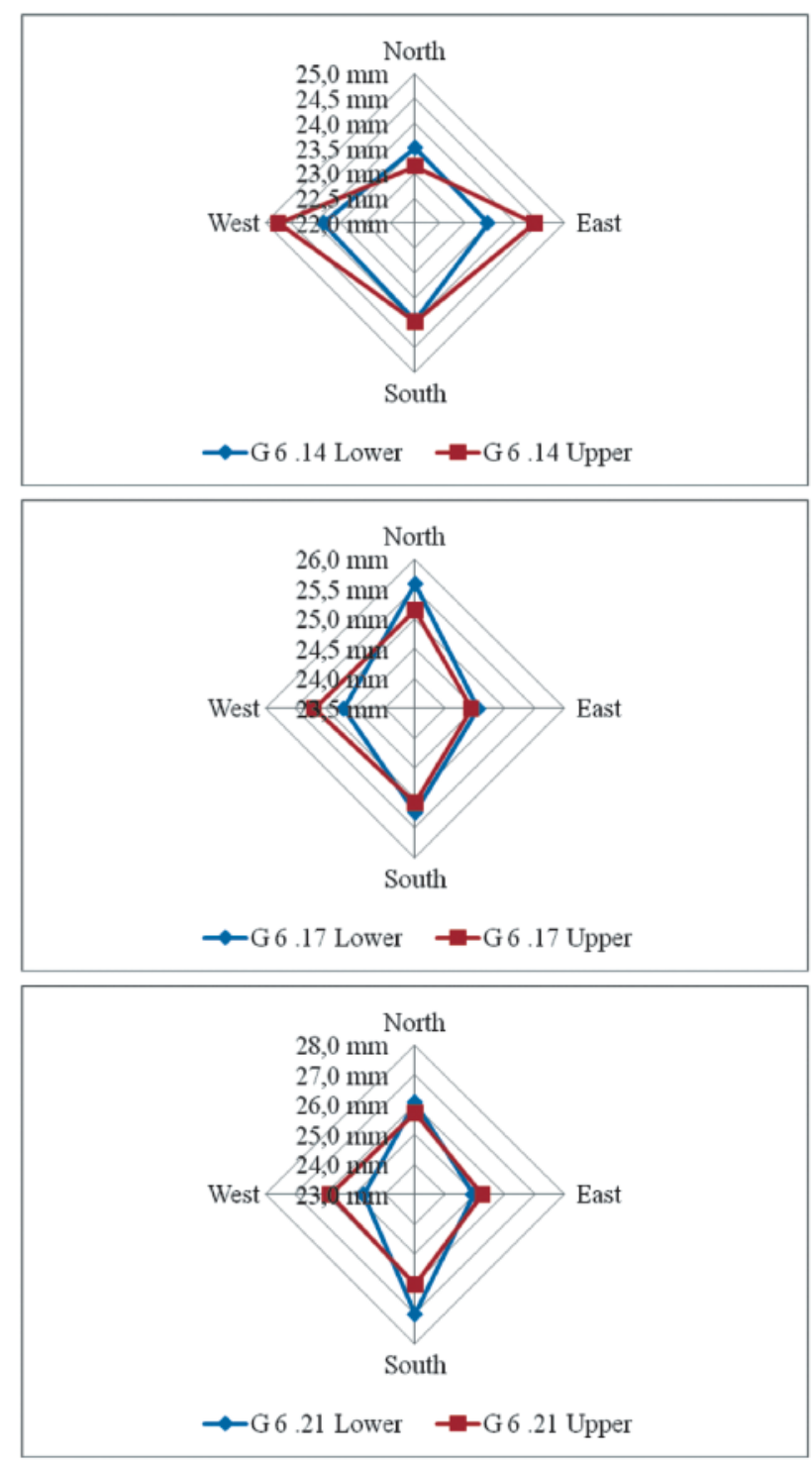

Fig. 4: The width in the function of time, orientation and height in the case of Germersdorfi [mm] 
This figure consists of three parts, too, and shows the values of widths for Germersdorfi in three sampling dates.

In the case of Stella the differences of the average widths varied between $2-15 \%$ in the function of orientation. The maximum deviation was measured at the last sampling time, i.e. when the cherries were ripe. The differences of the average widths varied between $1-11 \%$ when the lower and upper sampling locations were compared.

The changes can be seen clearly in Fig. 5, considering the sampling time, the orientation and the height of the foliage. This figure also consists of three parts, and shows the values of widths for Stella in three sampling dates.

\section{Individual fruit mass}

The values for the individual fruit mass for the three varieties of cherry are given in Table 2. The samples were collected from two different heights and four different directions according to the points of the compass.

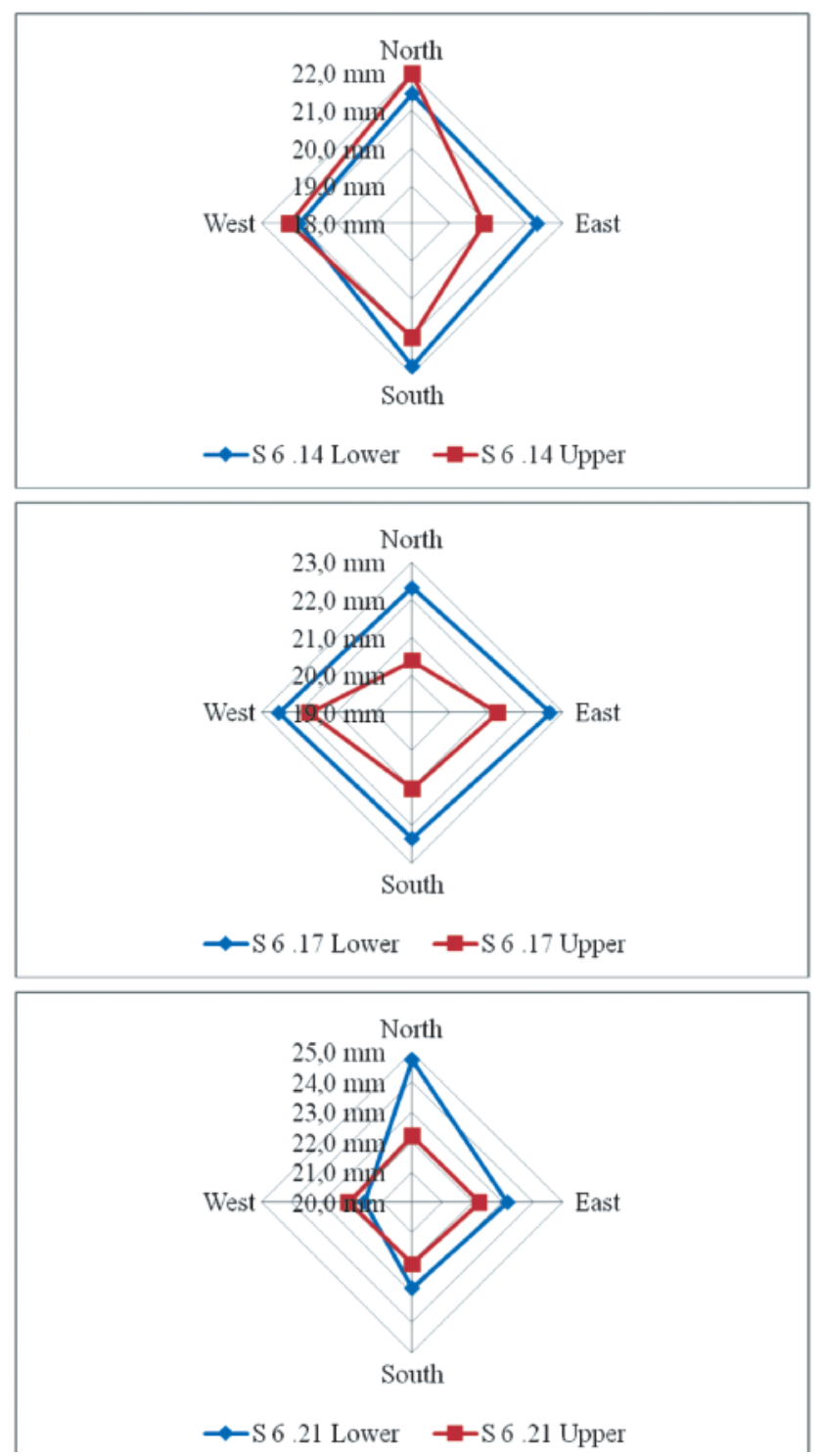

Fig. 5: The width in the function of time, orientation and height in the case of Stella $[\mathrm{mm}]$
Table 2: The values for the individual fruit mass

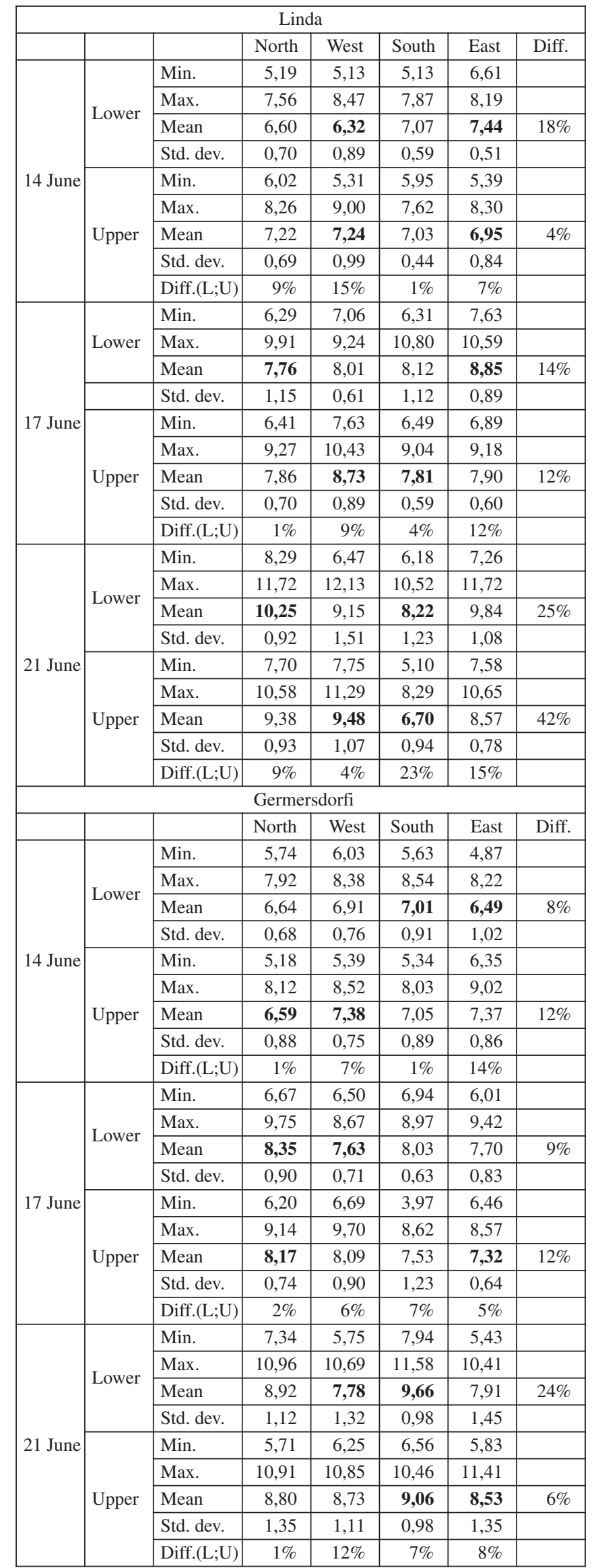




\begin{tabular}{|c|c|c|c|c|c|c|c|}
\hline \multicolumn{8}{|c|}{ Stella } \\
\hline & & & North & West & South & East & Diff. \\
\hline \multirow{9}{*}{14 June } & \multirow{4}{*}{ Lower } & Min. & 4,59 & 4,35 & 4,21 & 4,28 & \\
\hline & & Max. & 6,49 & 6,02 & 6,95 & 7,42 & \\
\hline & & Mean & 5,69 & 5,41 & 6,16 & 5,93 & $14 \%$ \\
\hline & & Std. dev. & 0,56 & 0,50 & 0,73 & 0,86 & \\
\hline & \multirow{5}{*}{ Upper } & Min. & 5,32 & 4,49 & 4,43 & 3,74 & \\
\hline & & Max. & 8,08 & 7,23 & 6,71 & 5,60 & \\
\hline & & Mean & 6,74 & 5,61 & 5,67 & 4,72 & $43 \%$ \\
\hline & & Std. dev. & 0,79 & 0,82 & 0,71 & 0,54 & \\
\hline & & Diff.(L;U) & $18 \%$ & $4 \%$ & $9 \%$ & $26 \%$ & \\
\hline \multirow{9}{*}{17 June } & \multirow{4}{*}{ Lower } & Min. & 5,33 & 5,32 & 6,36 & 5,62 & \\
\hline & & Max. & 8,31 & 8,16 & 7,89 & 7,99 & \\
\hline & & Mean & 6,50 & 6,74 & 7,01 & 6,88 & $8 \%$ \\
\hline & & Std. dev. & 0,89 & 0,91 & 0,48 & 0,76 & \\
\hline & \multirow{5}{*}{ Upper } & Min. & 4,34 & 5,10 & 4,75 & 5,34 & \\
\hline & & Max. & 6,68 & 7,58 & 6,72 & 7,42 & \\
\hline & & Mean & 5,27 & 6,25 & 5,85 & 5,99 & $19 \%$ \\
\hline & & Std. dev. & 0,66 & 0,72 & 0,58 & 0,63 & \\
\hline & & Diff.(L;U) & $23 \%$ & $8 \%$ & $20 \%$ & $15 \%$ & \\
\hline \multirow{9}{*}{21 June } & \multirow{4}{*}{ Lower } & Min. & 6,31 & 5,13 & 6,03 & 5,95 & \\
\hline & & Max. & 10,35 & 7,42 & 8,77 & 8,75 & \\
\hline & & Mean & 8,53 & 5,98 & 7,21 & 7,37 & $43 \%$ \\
\hline & & Std. dev. & 1,28 & 0,64 & 0,72 & 0,67 & \\
\hline & \multirow{5}{*}{ Upper } & Min. & 5,21 & 4,77 & 4,91 & 5,06 & \\
\hline & & Max. & 9,05 & 8,18 & 7,89 & 7,81 & \\
\hline & & Mean & 6,80 & 6,56 & 6,73 & 6,65 & $4 \%$ \\
\hline & & Std. dev. & 0,99 & 0,88 & 0,78 & 0,88 & \\
\hline & & Diff.(L;U) & $26 \%$ & $10 \%$ & $7 \%$ & $11 \%$ & \\
\hline
\end{tabular}

According to the data, shown in the table, it can be generally concluded, that there is a substantial difference in the values of mass of samples taken from different heights and different directions.

Analysing the certain varieties, the differences of the average mass of Linda varied between $4-42 \%$ in the function of orientation. The maximum deviation was measured at the last sampling time, i.e. when the cherries were ripe. The differences of the average mass varied between 1-23\% when the lower and upper sampling locations were compared.

The changes can be seen clearly in Fig. 6, considering the sampling time, the orientation and the height of the foliage. This figure consists of three parts, and shows the values of mass for Linda in three sampling dates.

In the case of Germersdorfi the differences of the average mass varied between 6-24\% in the function of orientation. The maximum deviation was measured at the last sampling time, i.e. when the cherries were ripe. The differences of the average mass varied between 1-14\% when the lower and upper sampling locations were compared.

The changes can be seen clearly in Fig. 7, considering the sampling time, the orientation and the height of the foliage. This figure also consists of three parts, and shows the values of mass for Germersdorfi in three sampling dates.

In the case of Stella the differences of the average mass varied between $4-43 \%$ in the function of orientation. The maximum deviation was measured at the last sampling time, i.e. when the cherries were ripe. The differences of the

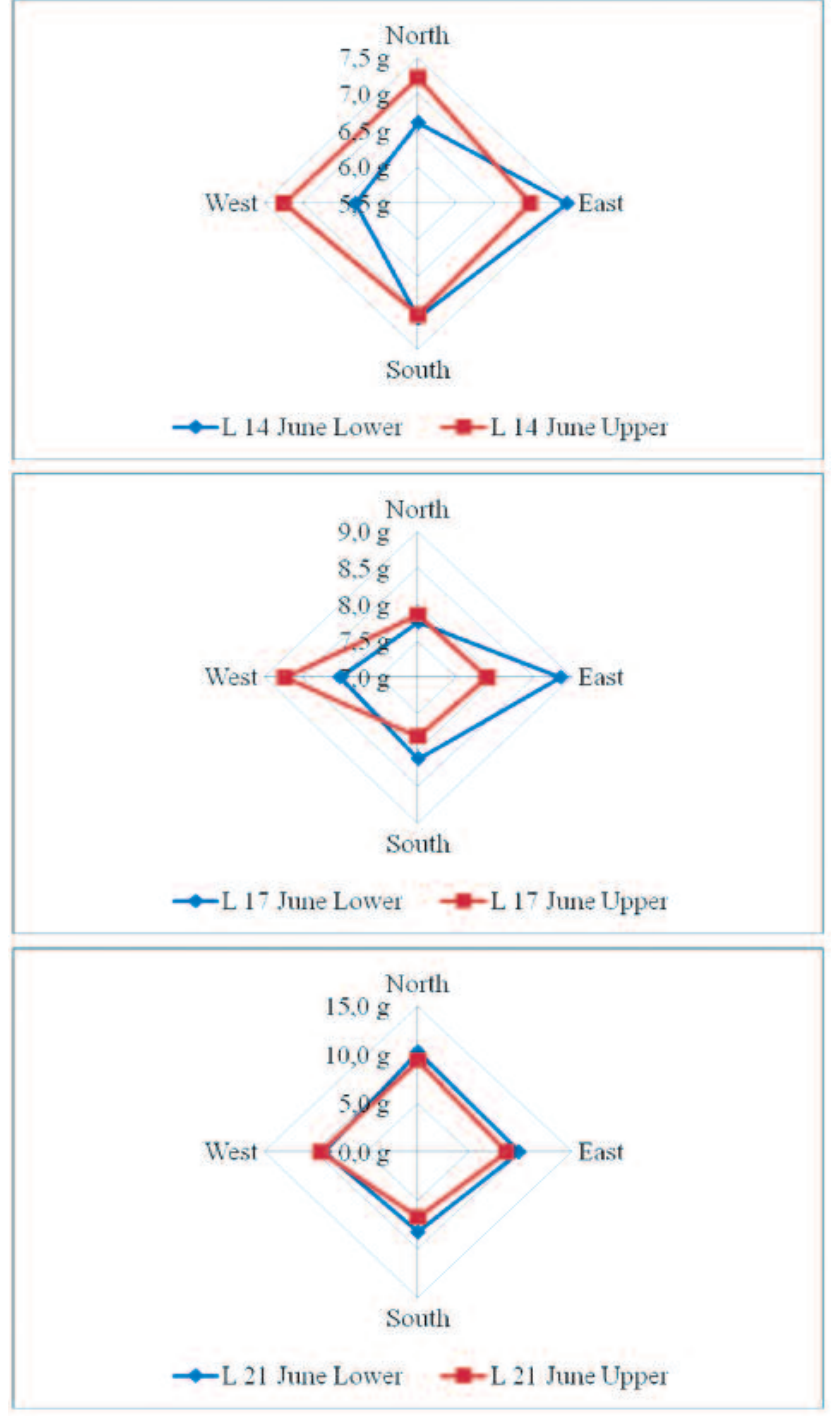

Fig. 6: The mass in the function of time, orientation and height In the case of Linda $[\mathrm{g}]$

average mass varied between 4-26\% when the lower and upper sampling locations were compared.

The changes can be followed in Fig. 8, considering the sampling time, the orientation and the height of the foliage. This figure also consists of three parts, and shows the values of mass for Stella in three sampling dates.

\section{Stone mass}

In order to determine the stone-pulp ratio, we have to measure the stone mass of the ripe cherries. These samples were collected on 21 June.

The values of the stone mass of the samples, taken from two different heights and four different directions, for three varieties of cherry are given in Table 3.

According to the data, shown in the table, it can be generally concluded, that there is some difference in the values of stone mass of samples taken from different heights and different directions.

Analysing the certain varieties, the differences of the average stone mass of Linda varied between 14-25\% in the 

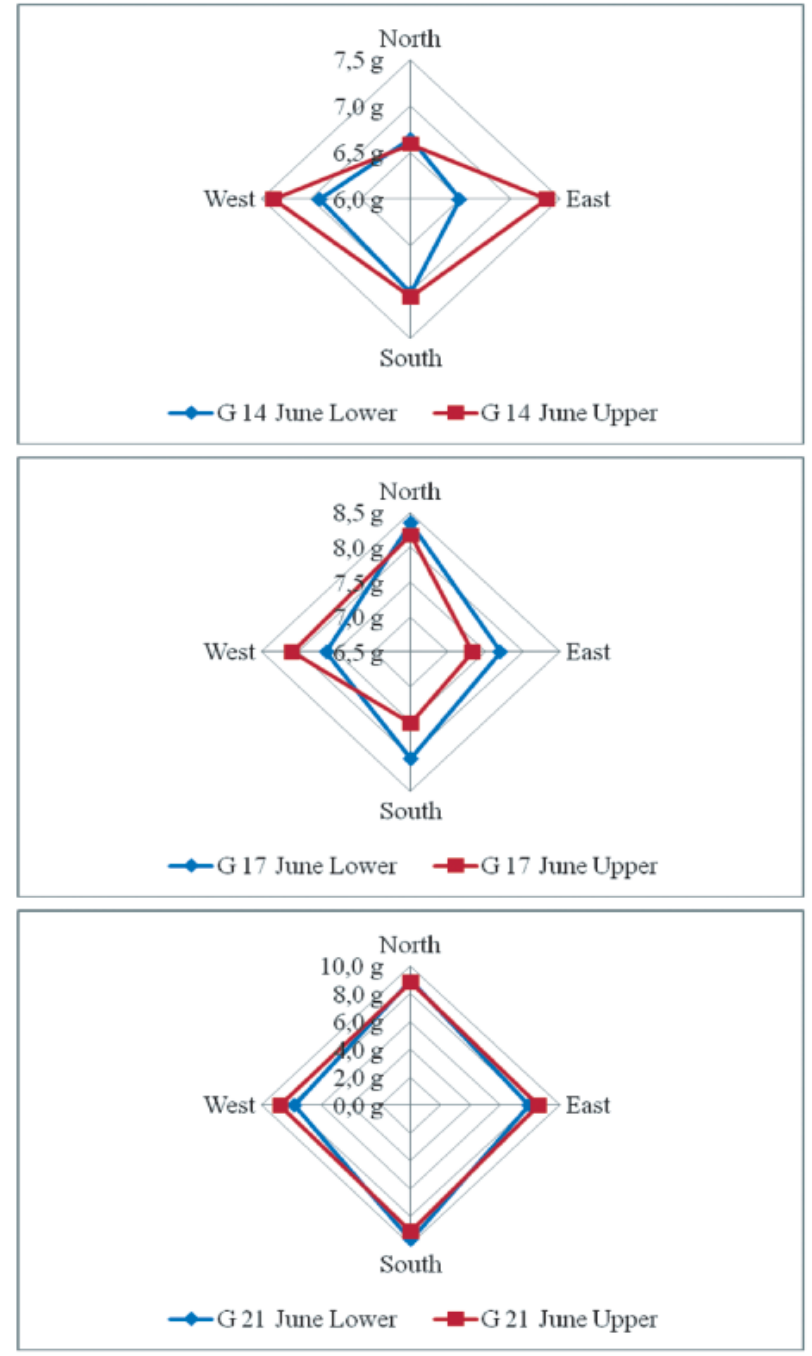

Fig. 7: The mass in the function of time, orientation and height in the case of Germersdorfi [g]

function of orientation. The differences of the average stone mass varied between $4-12 \%$ when the lower and upper sampling locations were compared.

The changes can be seen clearly in Fig. 9, considering the orientation and the height of the foliage, and make it possible to analyse the changes of the stone mass.

In the case of Germersdorfi the differences of the average stone mass varied between 6-13\% in the function of orientation. The differences of the average stone mass varied between 1-15\% when the lower and upper sampling locations were compared.

The changes can be seen clearly in Fig. 10, considering the orientation and the height of the foliage, and make it possible to analyse the changes of the stone mass.

In the case of Stella the differences of the average stone mass varied between 16-30\% in the function of orientation. The differences of the average stone mass varied between 3-14\% when the lower and upper sampling locations were compared.

Fig. 11 shows the changes of stone mass, considering the changes of foliage height and orientation, and makes it possible to analyse the changes of the stone mass.

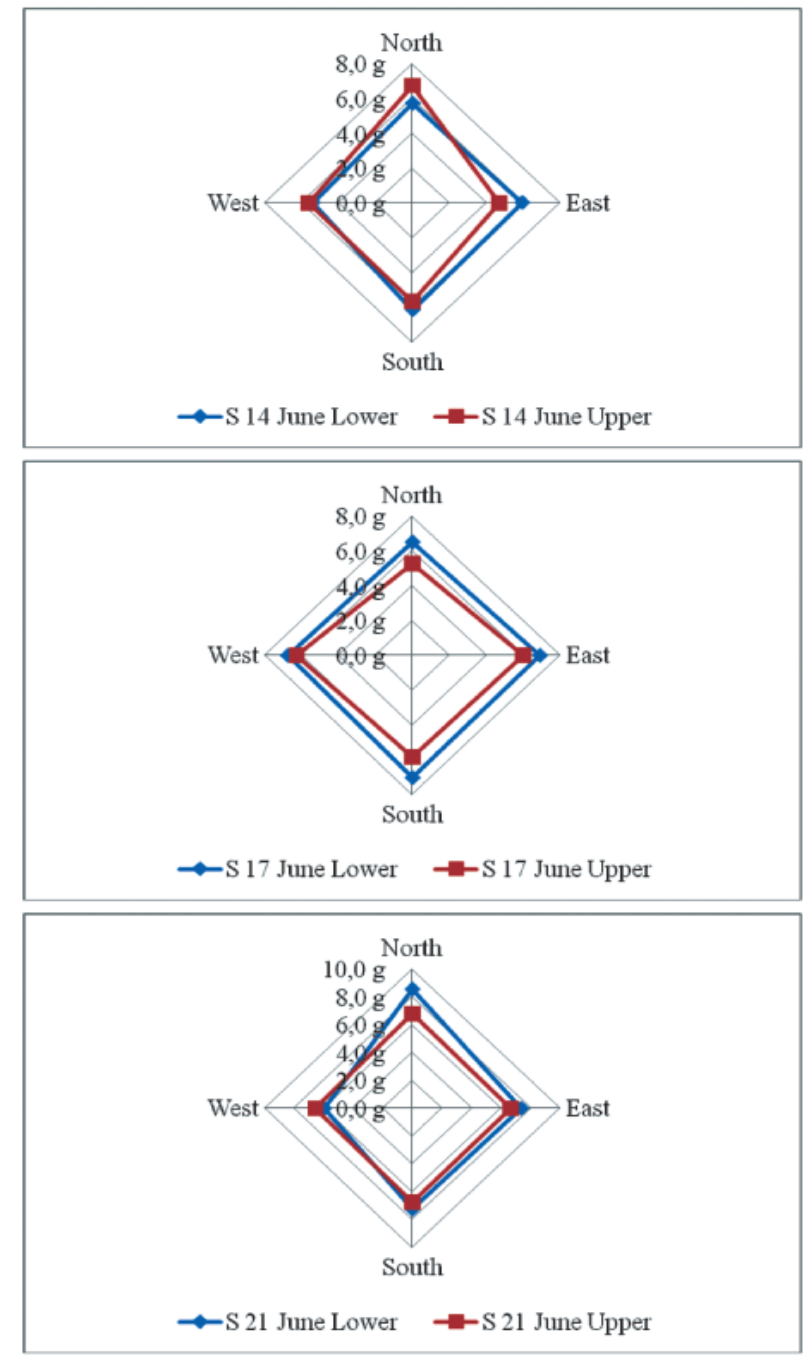

Fig. 8: The mass in the function of time, orientation and height in the case of Stella $[\mathrm{g}]$

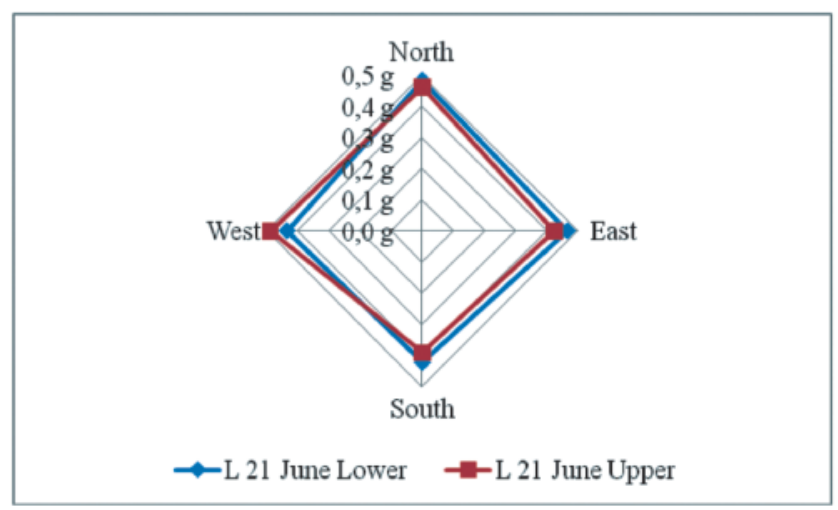

Fig. 9: Stone mass in the function of orientation and height in the case of Linda $[\mathrm{g}]$

\section{Stone-pulp ratio}

The values of the stone-pulp ratio of the samples, taken from two different heights and four different directions, for three varieties of cherry are given in Table 4.

In general it can be concluded that the average values of 
Table 3: The values of the stone mass

\begin{tabular}{|c|c|c|c|c|c|c|c|}
\hline \multicolumn{8}{|c|}{ Linda } \\
\hline & & & North & West & South & East & Diff. \\
\hline \multirow[t]{9}{*}{21 June } & Lower & Min. & 0,36 & 0,32 & 0,36 & 0,39 & \\
\hline & & Max. & 0,58 & 0,51 & 0,47 & 0,52 & \\
\hline & & Mean & 0,48 & 0,43 & 0,42 & 0,47 & $14 \%$ \\
\hline & & Std. dev. & 0,06 & 0,06 & 0,03 & 0,04 & \\
\hline & Upper & Min. & 0,37 & 0,36 & 0,31 & 0,33 & \\
\hline & & Max. & 0,50 & 0,57 & 0,45 & 0,49 & \\
\hline & & Mean & 0,46 & 0,49 & 0,39 & 0,42 & $25 \%$ \\
\hline & & Std. dev. & 0,03 & 0,05 & 0,05 & 0,04 & \\
\hline & & Diff.(L;U) & $4 \%$ & $12 \%$ & $8 \%$ & $10 \%$ & \\
\hline \multicolumn{8}{|c|}{ Germersdorfi } \\
\hline & & & North & West & South & East & Diff. \\
\hline \multirow[t]{9}{*}{21 June } & Lower & Min. & 0,32 & 0,28 & 0,32 & 0,31 & \\
\hline & & Max. & 0,43 & 0,42 & 0,47 & 0,44 & \\
\hline & & Mean & 0,38 & 0,35 & 0,39 & 0,37 & $13 \%$ \\
\hline & & Std. dev. & 0,03 & 0,04 & 0,05 & 0,03 & \\
\hline & Upper & Min. & 0,32 & 0,34 & 0,35 & 0,28 & \\
\hline & & Max. & 0,44 & 0,49 & 0,45 & 0,45 & \\
\hline & & Mean & 0,38 & 0,40 & 0,39 & 0,37 & $6 \%$ \\
\hline & & Std. dev. & 0,03 & 0,05 & 0,03 & 0,05 & \\
\hline & & Diff.(L;U) & $1 \%$ & $15 \%$ & $0 \%$ & $2 \%$ & \\
\hline \multicolumn{8}{|c|}{ Stella } \\
\hline & & & North & West & South & East & Diff. \\
\hline \multirow[t]{9}{*}{21 June } & Lower & Min. & 0,32 & 0,30 & 0,30 & 0,26 & \\
\hline & & Max. & 0,51 & 0,44 & 0,52 & 0,49 & \\
\hline & & Mean & 0,40 & 0,36 & 0,41 & 0,36 & $16 \%$ \\
\hline & & Std. dev. & 0,05 & 0,04 & 0,05 & 0,05 & \\
\hline & Upper & Min. & 0,37 & 0,30 & 0,29 & 0,23 & \\
\hline & & Max. & 0,49 & 0,44 & 0,43 & 0,38 & \\
\hline & & Mean & 0,41 & 0,38 & 0,36 & 0,32 & $30 \%$ \\
\hline & & Std. dev. & 0,04 & 0,04 & 0,03 & 0,05 & \\
\hline & & Diff.(L;U) & $4 \%$ & $3 \%$ & $14 \%$ & $12 \%$ & \\
\hline
\end{tabular}

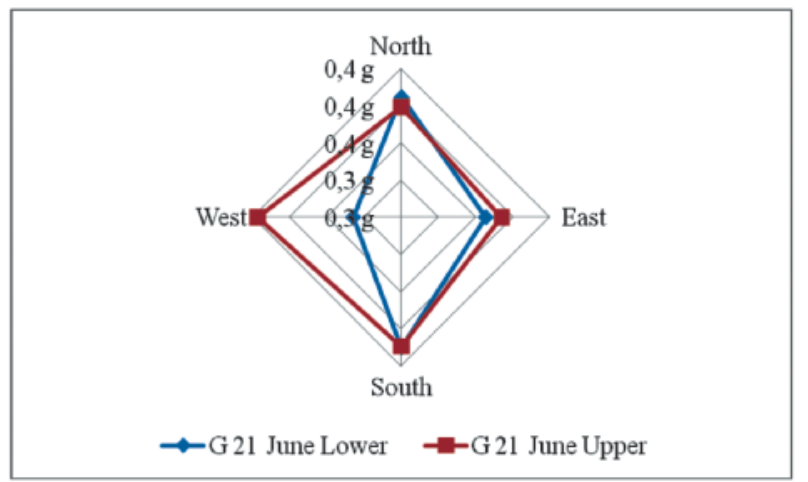

Fig. 10: Stone mass in the function of orientation and height in the case of Germersdorfi $[\mathrm{g}]$

stone-pulp ratio of the samples are different in different heights and directions according to the points of the compass.

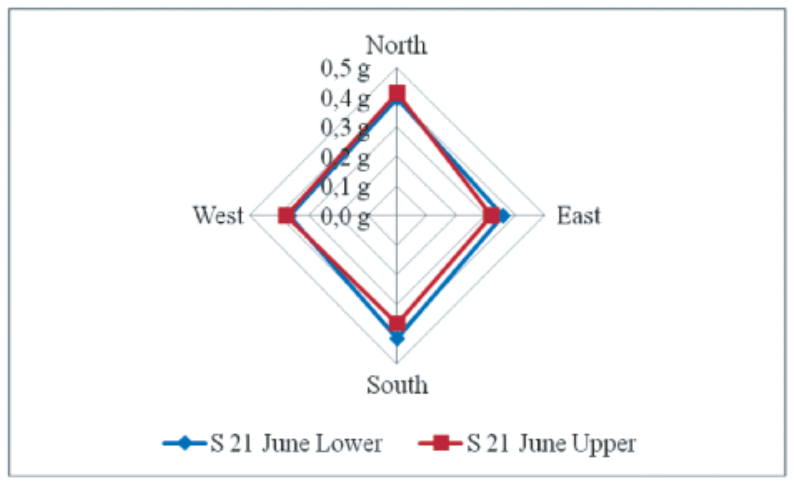

Fig. 11: Stone mass in the function of orientation and height in the case of Stella $[\mathrm{g}]$

Analysing the certain varieties, the differences of the average stone-pulp ratio of Linda varied between 11-20\% in the function of orientation. The differences of the average stone mass varied between 4-14\% when the lower and upper sampling locations were compared.

These differences can be seen clearly in Fig. 12, considering the orientation and the height of the foliage.

Table 4: The values of the stone-pulp ratio

\begin{tabular}{|c|c|c|c|c|c|c|c|}
\hline \multicolumn{8}{|c|}{ Linda } \\
\hline & & & North & West & South & East & Diff. \\
\hline \multirow{9}{*}{21 June } & \multirow{4}{*}{ Lower } & Min. & 3,60 & 4,39 & 4,58 & 3,96 & \\
\hline & & Max. & 6,06 & 6,16 & 7,29 & 5,99 & \\
\hline & & Mean & 4,97 & 5,02 & 5,52 & 5,01 & $11 \%$ \\
\hline & & Std. dev. & 0,70 & 0,51 & 0,83 & 0,55 & \\
\hline & \multirow{5}{*}{ Upper } & Min. & 4,11 & 4,63 & 5,14 & 4,35 & \\
\hline & & Max. & 6,35 & 6,59 & 9,44 & 6,13 & \\
\hline & & Mean & 5,24 & 5,46 & 6,28 & 5,22 & $20 \%$ \\
\hline & & Std. dev. & 0,64 & 0,58 & 1,05 & 0,47 & \\
\hline & & Diff.(L;U) & $5 \%$ & $9 \%$ & $14 \%$ & $4 \%$ & \\
\hline \multicolumn{8}{|c|}{ Germersdorfi } \\
\hline & & & North & West & South & East & Diff. \\
\hline \multirow{9}{*}{21 June } & \multirow{4}{*}{ Lower } & Min. & 3,33 & 3,79 & 3,61 & 4,10 & \\
\hline & & Max. & 5,61 & 5,72 & 4,83 & 6,89 & \\
\hline & & Mean & 4,57 & 4,74 & 4,21 & 4,97 & $18 \%$ \\
\hline & & Std. dev. & 0,65 & 0,71 & 0,34 & 0,83 & \\
\hline & \multirow{5}{*}{ Upper } & Min. & 3,61 & 3,88 & 3,99 & 3,59 & \\
\hline & & Max. & 6,34 & 6,16 & 5,64 & 5,67 & \\
\hline & & Mean & 4,61 & 4,82 & 4,53 & 4,66 & $7 \%$ \\
\hline & & Std. dev. & 0,81 & 0,67 & 0,42 & 0,64 & \\
\hline & & Diff.(L;U) & $1 \%$ & $2 \%$ & $7 \%$ & $7 \%$ & \\
\hline \multicolumn{8}{|c|}{ Stella } \\
\hline & & & North & West & South & East & Diff. \\
\hline \multirow{9}{*}{21 June } & \multirow{4}{*}{ Lower } & Min. & 4,09 & 4,95 & 4,10 & 3,67 & \\
\hline & & Max. & 6,50 & 8,38 & 6,95 & 7,46 & \\
\hline & & Mean & 4,93 & 6,55 & 6,10 & 5,13 & $33 \%$ \\
\hline & & Std. dev. & 0,61 & 0,88 & 0,70 & 0,89 & \\
\hline & \multirow{5}{*}{ Upper } & Min. & 4,87 & 5,28 & 4,83 & 4,01 & \\
\hline & & Max. & 9,68 & 6,96 & 8,63 & 6,30 & \\
\hline & & Mean & 6,60 & 6,11 & 5,80 & 5,05 & $31 \%$ \\
\hline & & Std. dev. & 1,27 & 0,59 & 0,99 & 0,62 & \\
\hline & & Diff.(L;U) & $34 \%$ & $7 \%$ & $5 \%$ & $2 \%$ & \\
\hline
\end{tabular}




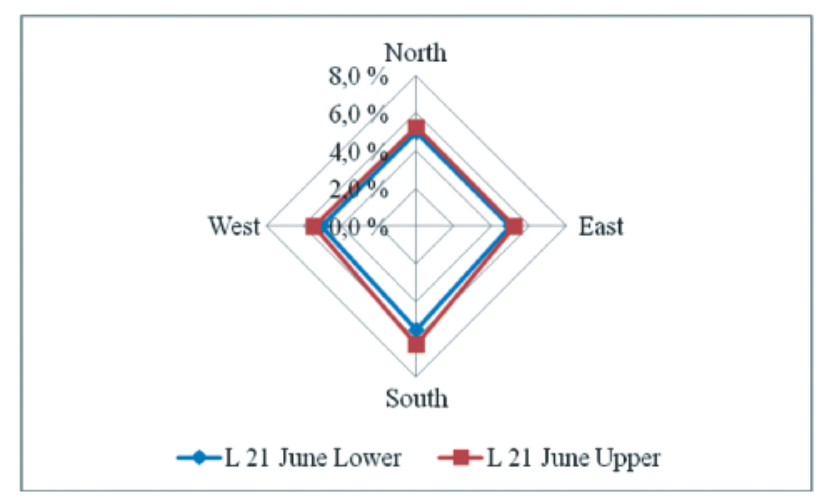

Fig. 12: Stone-pulp ratio in the function of orientation and height in the case of Linda [\%]

In the case of Germersdorfi the differences of the average stone-pulp ratio varied between $7-18 \%$ in the function of orientation. The differences of the average stone-pulp ratio varied between 1-7\% when the lower and upper sampling locations were compared (Fig. 13).

In the case of Stella the differences of the average stonepulp ratio varied between $31-33 \%$ in the function of orientation. The differences of the average stone-pulp ratio varied between 2-34\% when the lower and upper sampling locations were compared (Fig. 14).

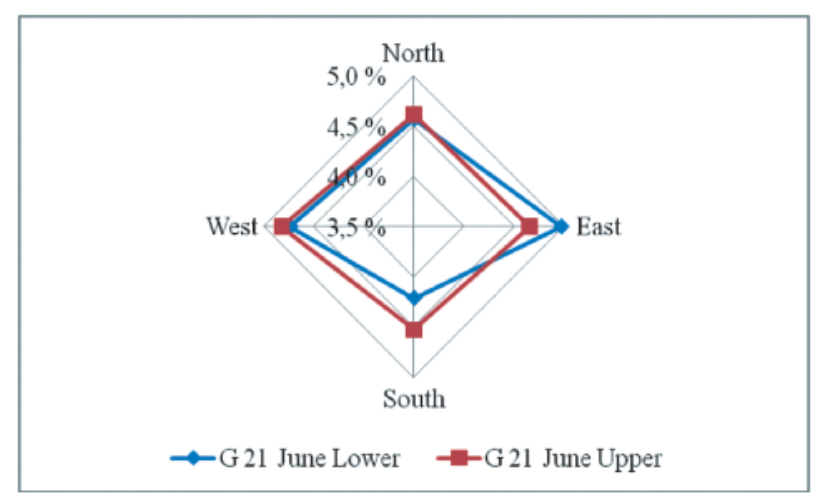

Fig. 13: Stone-pulp ratio in the function of orientation and height in the case of Germersdorfi [\%]

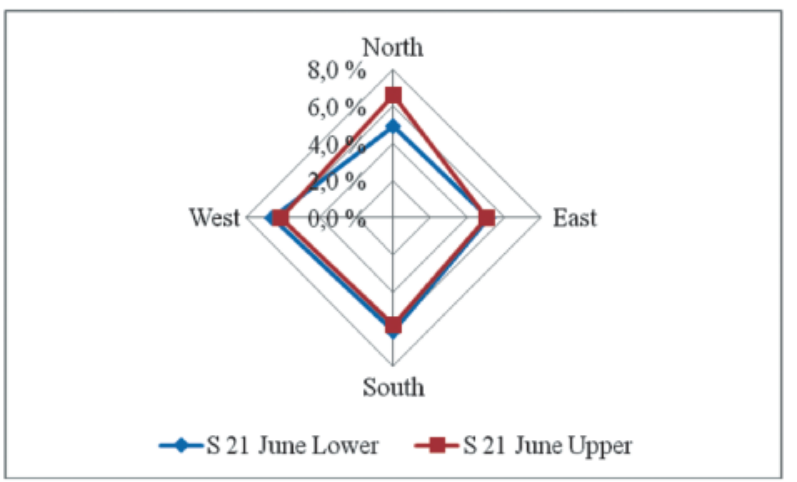

Fig. 14: Stone-pulp ratio in the function of orientation and height in the case of Stella [\%]

\section{Conclusions}

1. There are differences in the size of cherries sampled from different directions according to the points of the compass. The differences are sometimes close to $20 \%$.

2. There are also differences in the size of cherries sampled from different heights of the foliage. The differences are sometimes close to $15 \%$.

3. The differences are greater when samples taken from different orientations of the foliage were examined, than samples from different height.

4. There are differences in the individual mass of the cherries sampled from different directions according to the points of the compass. The differences are sometimes greater than $40 \%$.

5. There are also differences in the individual mass of cherries sampled from different heights of the foliage. The differences are greater than $25 \%$.

6 . The differences in individual mass are greater when samples taken from different orientations of the foliage were examined, than samples from different height.

7. The stone-pulp ratio of cherries sampled from different orientations is different; the differences are sometimes greater than $30 \%$.

8. There are also differences when the samples were collected from different height of the foliage. These differences can be over $30 \%$.

9. There are not significant differences when samples taken from different orientations of the foliage were examined, than samples from different height.

10. Overall, therefore, it can be concluded that a representative sample in a cherry orchard can only be obtained if the samples are collected from different orientations and heights of the foliage.

\section{Aknowledgement}

This work was financed by NFÜ TECH_08-A3/22008-0373 grant.

\section{References}

Csizmazia, Z. \& Polyák, N. I. (2004): Physical Properties of Green-Pea Seeds. IAMFE-RUSSIA 2004. 12th International Conference and Exhibition on Mechanization of Field Experiments. St. Petersburg-Pushkin, Russia. Proceedings, 371-375.

Csizmazia, Z. \& Polyák, N. I. (2004): The Physical Characteristics of Hemp Seed. Hungarian Agricultural Engineering, 17: 60-62.

Polyák, N.I. (1998): Some Physical Characteristics of Seeds. IAMFE-ARGENTINA, 98. First Latin American IAMFE Conference and Exhibition. Proceedings, 247-255.

Polyák, N.I. \& Csizmazia, Z. (2003): Physical Properties of Seeds of Vegetables. Hungarian Agricultural Engineering, 16: 35-37.

Polyák, N.I., Csizmazia, Z. \& Ancza, E. (2010): Some physical properties of sweet cherries. International Journal of Horticultural Science, 16 (1): 63-70. 